\title{
SiM
}

\section{Ascertaining Elk Impacts on Plant Communities}

\author{
By Charles G. Johnson, Marty Vavra, Mitch Willis, and Catherine G. Parks
}

\section{On the Ground}

- Managers charged with managing landscapes influenced by elk are challenged to establish monitoring protocols that identify when impacts are responsible for declining ecological condition.

- We assessed the impact of elk herbivory on plant communities on an elk winter range by comparing canopy cover of common species that represented subjectively selected heavy and light elk impacts.

- Winter elk use has little direct impact on existing bunchgrasses, but winter elk traffic disrupts soils and provides the potential for invasive plant establishment.

Keywords: trampling, herbivory, plant communities, elk, winter range.

Rangelands 35(3):11-15

doi: 10.2111/RANGELANDS-D-12-00081.1

(C) 2013 The Society for Range Management

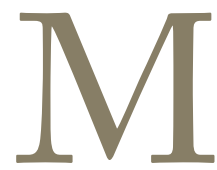

anagers charged with managing landscapes influenced by ungulates are challenged to establish monitoring protocols that identify when impacts are responsible for declining ecological condition. It is difficult to develop monitoring protocols that result in defensible data under the time and resource constraints realized by land managers. Ungulates may impact their environment by foraging and trampling, which influence plant composition, abundance, stature, and stability. Through foraging, ungulates directly impact their environment by influencing changes in the plant community by suppressing selected forage plants. ${ }^{1}$ Altered species composition due to selective foraging is a general feature of plant-ungulate interactions extending across biomes. ${ }^{2}$ Ungulates are important agents of environmental change, acting to create spatial heterogeneity, accelerate successional processes, and control the switching of ecosystems between alternative states. ${ }^{3}$ Although foraging is an active, immediate action, the effects or impacts of that action are long-term in nature and are masked in short-term investigations. Ungulate herbivory has been termed a chronic disturbance over time equal to events such as fire. ${ }^{1}$ Additionally, ungulate trampling causes soil disturbance and the opportunity for invasive species to establish. ${ }^{4,5}$ Plant responses to ungulate use can be the result of a plant-by-plant replacement process where tramplingresistant plants have an advantage. ${ }^{6}$

We assessed the impact of elk herbivory on plant communities on an elk winter range in northeastern Oregon. We compared canopy cover of common species from subsamples that represented subjectively selected heavy and light elk impacts observed at the final sampling. Criteria for judging degree of elk use were presence of animals, pellet group counts along transects, hoof marks, soil displacement, and soliflucted soils attributed to elk use on steeper slopes.

\section{Study Area}

This study was initiated in 1994 by request of the WallowaWhitman National Forest Supervisor to provide information to assist in the management of a portion of Hells Canyon National Recreation Area in northeast Oregon. Land managers had perceived elk to be negatively impacting plant community integrity. Previously established vegetation trend plots were available to reread for this study of elk impacts.

Hells Canyon National Recreation Area straddles the border between northeastern Oregon and adjacent Idaho as defined by the Snake River. The portion of the canyon selected for the study involved the Canyon Allotment, 32,600 ha encompassing an elevation range from $305 \mathrm{~m}$ along the river to 1,525 $\mathrm{m}$ at the brow of the canyon rim. Plant associations are predominately bunchgrasses with interspersed forest and shrubland associations where soil and moisture conditions permit (Fig. 1). The Canyon Allotment is contained within the Snake River Wildlife Management Unit (SRWMU), a sampling unit for the Oregon Department of Fish and Wildlife.

\section{History of Ungulate Use}

In 1975 the allotments encompassing our sampling sites accounted for 3,500 animal-unit months of use by cattle. Rocky 


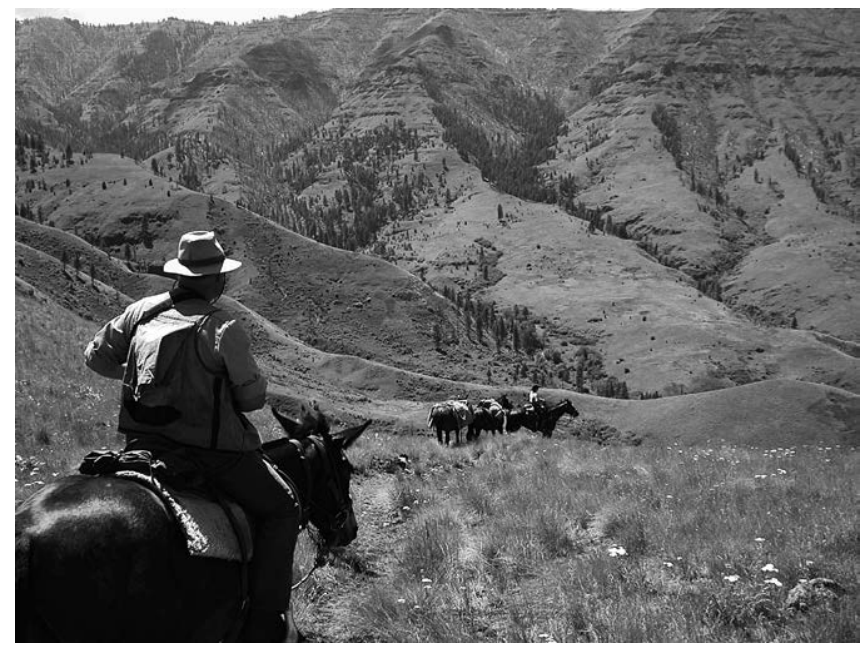

Figure 1. Charlie Johnson viewing a landscape typical of the study area.

Mountain elk populations for the SRWMU averaged about 2,000 prior to 1979 (Fig. 2). ${ }^{7}$ In 1979 cattle were removed from the allotments. The elk population, which averaged 3,134 animals in 1965, began increasing about 1978, and peaked in 1987 at 5,168 animals. Elk use was typically concentrated on the structural bench zone (mid-elevation) in the spring, and more dispersed the remainder of the year.

\section{How We Did It}

Permanent plots had been established in 1979 on plant associations to monitor potential ecological change over time. Forty-three plant associations that had elk use were selected based on herd counts when present, pellet group counts along transects, hoof marks, soil displacement, and soliflucted soil attributed to animal movements (file data, Wallowa-Whitman National Forest Supervisor's Office). Associations included 17 dominated by Idaho fescue (Festuca idahoensis Elmer), 20 dominated by bluebunch wheatgrass (Psuedoroegneria spicata [Pursh] A. Love), two open forest associations, and four shrub associations. Plots were located on ridgetops, and over an elevational gradient identified as upper slope, bench, and lower slope. Figure 1 illustrates both plant associations and the upper slope and bench categories. There was no attempt to incorporate an experimental design in the monitoring protocols. On each plant association, a plot was established consisting of two line transects $30.5 \mathrm{~m}$ along which twenty $0.09 \mathrm{~m}^{2}$ quadrats were established. Presence or absence of plant species and percentage canopy coverage were recorded for each quadrat. At each transect location general observations were recorded relating to soil sloughing, hoof displacement of soils, terracette breakdown, and solifluction (plastic soil movements).

These plots were again read in 1996. To establish the ecological interpretation of the data, we then established a set of criteria that categorized the 1996 plant associations as either elk-impacted or elk-nonimpacted. Separation was based on

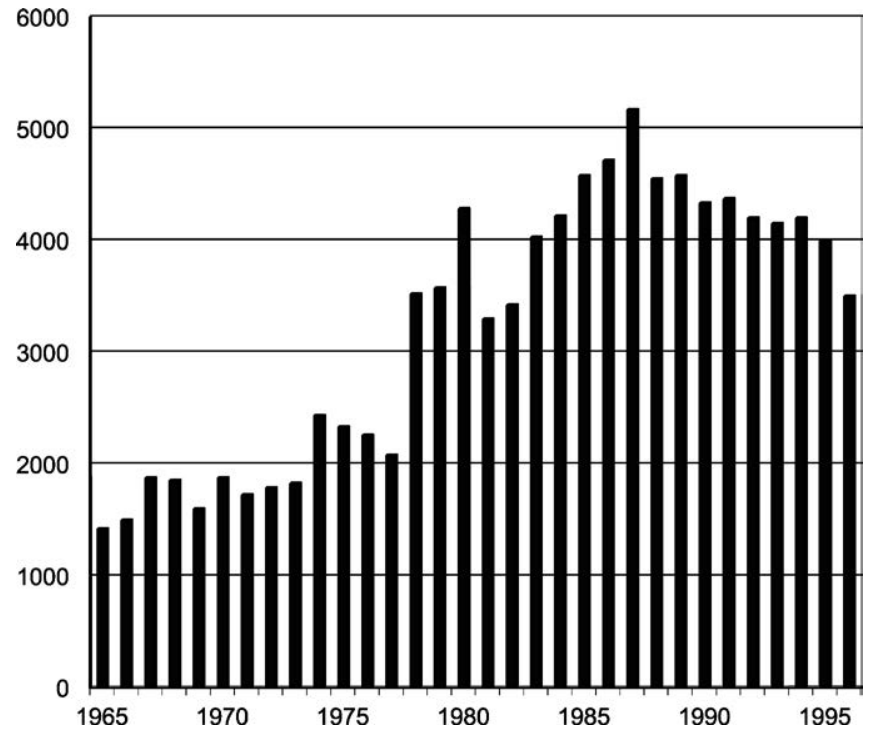

Figure 2. Post-season elk abundance, Snake River Wildlife Management Unit, Oregon, 1965-2000.

plant associations suggesting change in ecological trend and the same subjective observations utilized when the study was initiated: herd counts when present, pellet groups along transects, hoof marks, soil displacement, and soliflucted soils attributed to animal movements. In 1979 all associations were categorized as elk impacted, while, in 1996, 22 plant associations were categorized as impacted and 21 as nonimpacted by elk.

We investigated differences in canopy cover of perennial and annual grasses, introduced and native; all bunchgrasses; key species-Kentucky bluegrass (Poa pratensis L.), Sandberg bluegrass (Poa secunda J. Presl), bluebunch wheatgrass, Idaho fescue, North Africa grass (Ventenata dubia [Leers] Coss.), prairie junegrass (Koeleria macrantha [Ledeb. J. A. Shchultes]), cheatgrass (Bromus tectorum L.), and threepetal bedstraw (Galium trifidum L.) -increasers and decreasers; and other plant/soil-associated variables (moss, lichens, bare ground, bedrock, rock, gravel, and litter).

We used multivariate analysis of variance to test for initial differences (1979 data) between plant associations categorized in 1996 as impacted and those as nonimpacted. Twosample, equal variance $t$ tests were used to assess impacted versus nonimpacted plant associations during the initial 1979 visit. Based on those $t$ tests we assumed that there were no differences among plant associations (elk impacted versus nonimpacted) at the time of the 1979 visit. Pair wise $t$ tests were used to test for differences between the 1979 and 1996 visits on nonimpacted and elk-impacted plant associations.

\section{Wintering Elk Impacts}

Dynamics of vegetation change in a canyon setting can be summarized as follows. Natural erosive events triggered by slumps, slope movements, and slope wash are factors that affect vigor and vitality of bunchgrass communities, but drought cycles are 
strongly influential. Utilization by ungulates (cattle, sheep, elk, and deer), rodents, and insects has also been an historic agent of vegetation change in the canyon lands. Displacement of plants during late winter and early spring by large animals has been a frequent cause of perennial vegetation loss and/or change in species. However, there is no single factor acting alone that creates vegetation change. In the classic case, changes are directional in a successional sense, and these successional pathways are predictable for each plant association. ${ }^{8}$ As perennial grasses (i.e., Idaho fescue) decline from disturbance factors, increases by competitive forbs or annual vegetation occur. The site then retrogresses to an earlier seral state in the successional pathway. A cessation in large-scale perturbations can promote the same perennial grasses to outcompete the native perennial forbs and annual vegetation to initiate a progressive succession to a later seral stage unless a threshold has been crossed. Given that our study sites were established immediately after cessation of cattle grazing, one might surmise that ecological improvement of the landscape would occur because of the release from cattle herbivory. Conversely, legacy effects from cattle grazing might confound expected secondary succession.

On plant associations impacted by elk the paired $t$ test indicated significant increases to annual grass cover and North Africa grass, which would suggest a downward trend (Table 1). Supporting that would be the significant decline in moss, suggesting a trampling effect, which would contribute to the increase in annual grasses. No significant changes were noted for perennial grasses, bluebunch wheatgrass, Idaho fescue, or perennial forbs. Changes on the elk-impacted sites, however, were not dramatic in that the perennial grass component including key native perennial species, bluebunch wheatgrass and Idaho fescue, remained stable. These results appear to be similar to those of another study in southeastern Washington $^{9}$ in that on an elk winter range the bunchgrass component remained intact but soil disturbances might have been critical to range condition. Likewise, winter grazing by elk had no effect on plant productivity of upland steppe on Yellowstone's northern winter range. ${ }^{10}$ In Montana removal of herbage from Idaho fescue plants early in the growing season or after plants senesced did not cause damage. ${ }^{11}$ Additionally, our results are consistent with others ${ }^{2}$ who found spring use of plants by ungulates during early phenological stages followed by ungulate migration and an absence of herbivory during the remainder of the growing season provided maintenance of the preferred and palatable species (Idaho fescue and bluebunch wheatgrass).

Observational data provided perhaps the strongest argument for potential resource damage caused by elk. The general degree of elk traffic, trails, bed grounds, and solifluction was recorded in field notes. Soil disturbance of the interspaces by ungulate traffic could have provided the potential seedbed for annual invaders and loss of germinating bunchgrasses. The appearance of the invasive annual North Africa grass and its increase on elk-impacted sites was an indicator of potential disruption of the communities and should be of great concern for the long-range health of Hells Canyon plant communities.

Is elk trampling the causal mechanism? The principal effect of elk using steep, canyon slope bunchgrass communities was observed as the displacement of plants caused either by trampling or secondarily by slope movements displacing the plants. Snowmelt, ice melt, and rains saturate the soils in late winter and early spring. Soils can easily displace on steep slopes from direct hoof impact or by indirect causes attributed to trampling through plastic flow (solifluction) of the supersaturated soils. Revegetation and elk-exclusion influence on ground cover density (canopy cover) and soil erosion were observed on an elk winter range in Montana. ${ }^{12}$ Over the extent of this Montana study, ground cover density increased on all treatments, but most on protected and reseeded plots and least on grazed unseeded plots. Soil erosion increased as "ground cover density" decreased below 70\% and soil bulk density increased above $1.04 \mathrm{~g} / \mathrm{cc}^{12}$

Is North Africa grass invasion an indicator of site degradation, facilitated by elk impacts, which will eventually transition the community to a new steady state? In our study the increase in annual grasses and the decline in moss and bare ground may be attributed to elk traffic. ${ }^{8}$ Cattle grazing prior to our study occurred in summer when soils were relatively dry and stable. In spring when soils were saturated, elk movement through the plant communities caused disruption of soil surface integrity in the interspaces between bunchgrass plants. This disruption was indicated by the decline in moss cover and may have resulted in the increase of the invader North Africa grass. North Africa grass increased across elk impacted sites on all land types, upper and lower slopes, ridgetops and benches, and plant associations. Mature bunchgrasses are apparently well rooted and have been resistant to trampling damage as their cover has not declined. Unfortunately we did not identify bunchgrass age classes in our plots, so we were unable to quantify lack of recruitment, a potential key indicator of community integrity. However, field notes recorded that perennial bunchgrasses were relict, and there were no new plants. We suspect loss of seedling bunchgrass plants from trampling and solifluction. Similar observations were made on a comparable elk winter range in southeastern Washington. ${ }^{9}$ In that study, bluebunch wheatgrass was not physiologically impacted by winter elk use. However, observations revealed continued soil loss through washes, slips, and surface runoff, early spring trampling in water-saturated soil, trails that accelerated erosion, low density of vegetation, scarcity of litter, and persistence of cheatgrass on the drier exposures and other factors that the range was not in good condition. Other indicators of potential decline in ecological integrity were the decline in moss cover and the increase in bare ground.

\section{Management Implications}

Establishment of the plots described here occurred at a very opportune time-livestock had just been removed from the range and elk numbers were beginning to increase. Our data 
Table 1. Mean percentage cover of selected ecological assessment variables on impacted and nonimpacted sites, Hells Canyon, Oregon

\begin{tabular}{|c|c|c|c|c|c|c|c|c|}
\hline \multirow{2}{*}{ Variable } & \multicolumn{4}{|c|}{ Nonimpacted sites } & \multicolumn{4}{|c|}{ Impacted sites } \\
\hline & 1979 & 1996 & $\boldsymbol{P}^{*}$ & df & 1979 & 1996 & $\boldsymbol{P}^{*}$ & df \\
\hline Perennial grass & 26. $2 \pm 3.1$ & $30.0 \pm 3.7$ & 0.211 & 21 & $34.4 \pm 3.8$ & $34.2 \pm 3.2$ & 0.953 & 20 \\
\hline Introduced bunchgrassest & $7.5 \pm 2.9$ & $4.7 \pm 1.9$ & 0.109 & 21 & $5.7 \pm 3.0$ & $8.1 \pm 3.0$ & 0.185 & 20 \\
\hline Kentucky bluegrass & $1.4 \pm 1.3$ & $1.7 \pm 1.4$ & 0.090 & 21 & $3.1 \pm 2.2$ & $6.0 \pm 2.7$ & 0.175 & 20 \\
\hline Bluebunch wheatgrass & $13.1 \pm 2.1$ & $16.2 \pm 2.9$ & 0.189 & 21 & $15.5 \pm 3.0$ & $15.0 \pm 2.4$ & 0.803 & 20 \\
\hline Idaho fescue & $3.3 \pm 1.6$ & $7 \pm 3.3$ & 0.051 & 21 & $9.8 \pm 3.3$ & $7.6 \pm 3.0$ & 0.27 & 20 \\
\hline Annual grass & $8.7 \pm 2.2$ & $11.0 \pm 2.6$ & 0.240 & 21 & $12 \pm 3.1$ & $21.1 \pm 3.9$ & 0.034 & 20 \\
\hline Cheatgrass & $2.6 \pm 1.0$ & $1.9 \pm 0.7$ & 0.401 & 21 & $5.7 \pm 2.2$ & $1.2 \pm 0.5$ & 0.059 & 20 \\
\hline North Africa grass & $0.0 \pm 0.0$ & $0.1 \pm 0.1$ & 0.329 & 21 & $0.0 \pm 0.0$ & $7.3 \pm 3.4$ & 0.046 & 20 \\
\hline Moss & $17.2 \pm 3.8$ & $13.1 \pm 3.6$ & 0.180 & 21 & $10.5 \pm 2.3$ & $3.4 \pm 1.0$ & 0.002 & 20 \\
\hline Lichens & $0.6 \pm 0.5$ & $1.0 \pm 0.2$ & 0.268 & 21 & $0.0 \pm 0.0$ & $1.0 \pm 0.4$ & 0.026 & 20 \\
\hline Bare ground & $9.6 \pm 2.3$ & $11.7 \pm 2.5$ & 0.496 & 20 & $13.9 \pm 1.8$ & $19.7 \pm 3.6$ & 0.052 & 20 \\
\hline
\end{tabular}

* Probability, Paired $t$ test.

†Kentucky bluegrass, sand dropseed, and slimspike threeawn. 
do indicate a reduction in ecological integrity on elk impacted sites. The noted effects may be termed indirect as native bunchgrasses were not directly impacted by elk herbivory. Impacts to soils, however, likely provided the opportunity for North Africa grass to invade. Long-term ramifications from this invasion are as yet unknown. It does indicate the need to make subjective observations on soil impacts from elk traffic. Whether or not ecological integrity is continuing to decline, considering declining elk numbers, is unknown. A repeat sampling may be required. The increase in the invader North Africa grass on elk-impacted sites, however, is a strong indicator that integrity of the elk-impacted sites is at risk. At the very least, continued sampling of the area to track North Africa grass invasion, observe increases of other invasive plants, and monitor indicators of elk impact is suggested. Since this study North Africa grass has become a significant component of many of the xeric grasslands in northeastern Oregon.

\section{Acknowledgments}

This paper is dedicated to the memory of Dr Charles G. "Charlie" Johnson, whose outstanding contributions to the ecology of the Blue and Wallowa Mountains and Hells Canyon will be long remembered and much appreciated by natural resource managers and scientists and the public. We thank two anonymous reviewers for helpful comments on the manuscript.

\section{References}

1. Riggs, R. A., A. R. Tiedemann, J. G. Cook, T. M. Ballard, P .J. Edgerton, M. Vavra, W. C. Krueger, F. C. Hall, L. D. Bryant, L. L. Irwin, and T. DelCurto. 2000. Modification of mixed-conifer forests by ruminant herbivores in the Blue Mountains Ecological Province. Portland, OR, USA: USDA Forest Service Pacific Northwest Research Station. Report PNW-RP-527. 77 p.

2. Augustine, D. J., And S. J. McNaughton. 1998. Ungulate effects on the functional species composition of plant communities: herbivore selectivity and plant tolerance. Journal of Wildlife Management 62:1165-1183.
3. Новвs, N. T. 1996. Modification of ecosystems by ungulates. Journal of Wildlife Management 60:695-713.

4. Lonsdale, M. 1999. Global patterns of plant invasions and the concept of invisibility. Ecology 80:1522-1536.

5. Vavra, M., C. G. Parks, and M. J. Wisdom. 2007. Biodiversity, invasive species and herbivory: the good, the bad, and the ungulate. Forest Ecology and Management 246:66-72.

6. Hanley, T. A., and R. D. Tabor. 1980. Selective plant species inhibition by elk and deer in three conifer communities in western Washington. Forest Science 26:97-107.

7. Schomer, T. 1991. Analysis of big game statistics 1965-90. Wallowa-Whitman National Forest Technical Report (unpublished). $65 \mathrm{p}$.

8. Johnson, C. G., And S. A. Simon. 1987. Associations of the Wallowa-Snake Province. Portland, OR, USA: USDA Forest Service Pacific Northwest Region. Report R6-ECOL-TP255A-86. 399 p.

9. Buechner, H. K. 1952. Winter-range utilization by elk and mule deer in southeastern Washington. Journal of Range Management 5:76-80.

10. Coughenour, M. B. 1991. Biomass and nitrogen responses to grazing of upland steppe on Yellowstone's northern winter range. Journal of Applied Ecology 28:71-82.

11. Mueggler, W. F. 1967. Response of mountain grassland vegetation to clipping in southwestern Montana. Ecology 48:942-949.

12. Packer, P. E. 1963. Soil stability requirements for the Gallatin elk winter range. Journal of Wildlife Management 27:401-410.

Authors are Plant Ecologist (deceased), Malheur, Umatilla, and Wallowa-Whitman National Forests, USDA Forest Service (Johnson); Rangeland Scientist Emeritus, martinvavra@fs.fed. us (Vavra), and Research Ecologist (Parks), Forestry and Range Sciences Laboratory, USDA Forest Service Pacific Northwest Research Station, La Grande, OR 97850, USA; and Research Assistant (retired), Eastern Oregon Agricultural Research Center, Burns, OR 97720, USA (Willis). Funding for data collection was provided by the Wallowa-Whitman National Forest. 